\title{
The performances of partial shading adjuster for improving photovoltaic emulator
}

\author{
Razman Ayop ${ }^{1}$, Chee Wei Tan ${ }^{1}$, Syed Norazizul Syed Nasir ${ }^{1}$, Mohd Zaki Daud ${ }^{1}$, Lau Kwan Yiew ${ }^{1}$, \\ Norjulia Mohamad Nordin ${ }^{1}$, Abba Lawan Bukar ${ }^{2}$ \\ ${ }^{1}$ School of Electrical Engineering, Universiti Teknologi Malaysia, Johor, Malaysia \\ ${ }^{2}$ Department of Electrical and Electronic Engineering, Faculty of Engineering, University of Maiduguri, Maiduguri, Nigeria
}

\begin{abstract}
Article Info
Article history:

Received Sep 13, 2021

Revised Jan 20, 2022

Accepted Jan 27, 2022

\section{Keywords:}

Buck converter

Partial shading

PI controller

PV

Single diode model

ABSTRACT

A photovoltaic (PV) emulator (PVE) is essential equipment for the research and diagnostic of PV generation. It is a convenient, highly efficient, and low-cost approach when compared to controllable light sources. Nonetheless, the implementation of the partial shading capability in a PVE is highly limited in terms of efficiency, computation burned, number of power converters, and flexibility to change in the ambient condition. This paper proposes a partial shading adjuster for a PVE that can overcome the aforementioned limitations. The adjuster is applicable to the conventional PVE since it is based on an algorithm that can be added to the controller of the PVE. By adding the adjuster, the conventional PVE can emulate partial shading. The partial shading adjuster is added into a PVE that uses the direct referencing control strategy with the buck controller regulated by the proportional-integral controller. The results show that the PVE maintains its accuracy and produces a stable output voltage and current during the load changes when the adjuster is added. In conclusion, the proposed partial shading adjuster able to improve the capability of the PVE by providing a real-time partial shading capability.
\end{abstract}

This is an open access article under the CC BY-SA license.

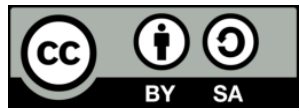

\section{Corresponding Author:}

Razman Ayop

School of Electrical Engineering, Faculty of Engineering, Universiti Teknologi Malaysia

81310, UTM Johor Bahru, Johor, Malaysia

Email: razman.ayop@utm.my

\section{INTRODUCTION}

Photovoltaic (PV) emulator (PVE) has become essential equipment for the research and development of the PV generation-based system. The common control strategy for the PVE is the direct referencing method. The control strategy consists of the standard PV model (PVM), proportional-integral (PI) controller, and buck converter. It is a simple control strategy that does not require any additional algorithm to operate since the operating point is determined by the transient response of the PVE. Nevertheless, this PVE does not consider the partial shading effect.

Partial shading occurs when the PV modules do not receive similar irradiance. This is due to shadows cast by clouds or buildings or the PV modules is not cleaned properly which leads to the dust layer. Computing partial shading is a difficult task especially if it is implemented into the PVE. As a result, the majority of the research does not include partial shading capability. There are 2 approaches that can be used to emulate partial shading for the PVE, which are the hardware and software approaches. For the hardware approach, the amplifier circuit combined with the PV cell is a simple PVE with partial shading capability [1]. This method amplifies the current-voltage (I-V) characteristic of the PV cell, which allows high-power emulation at a lower cost. Nonetheless, the method is highly inefficient since it operates in the linear region 
and is limited to the type of PV cell used. Another method is to build the PVE based on the transistor [2]. This method uses the PVM electrical circuit model as a reference and the diode presented in the PVM is replaced with the transistor. Although this method is simple and it requires a low cost to build, it has several limitations. This method requires multiple power sources, has low efficiency, and has a high ripple when emulating the certain region on the I-V characterised curve. Another method used to emulate partial shading is to combine several PVE [3]. This approach is suitable for a simple series configuration since the digital controller used needs to compute multiple PVM in real-time, which burden the digital controller and may affect the performance of the PVE. This method is also unable to emulate properly at a certain region of the I-V characteristic curve.

For the software approach, the control strategy is based on the common direct referencing method. The modification is done on the PVM to allow partial shading capability. If the PVM output is added together based on the PVM input, these PVMs are able to produce partial shading [4], [5]. This control strategy is called the PVM adder method. It is nearly similar to the multiple PVE method with the advantage of using only a single power converter. However, the digital controller stills need to compute multiple PVM to emulate the partial shading. To reduce the computation burden, the computation of the PVMs is conducted offline and the data is collected and placed in the look-up table (LUT) for the real-time operation [6]-[9]. Although this method solves the computation problem, it has a flexibility problem. This means that it is difficult to change the irradiance and temperature during real-time operation since the I-V curve is generated externally during the offline period.

The literature shows that emulating partial shading is a difficult task. When it comes to PVE with the partial shading capability, Recently, the single-based PVM with partial shading capability is developed, which significantly reduce the processing burden [10]. Therefore, this model is suitable to solve the limitation faced by the PVM adder method. This paper presents a new method for the PVE with the ability to produce partial shading based on the software approach. It uses a new adjuster that can produce partial shading by only adjusting the input of the standard PVM. This PVM is based on the single diode model with a series resistor or 1D1R model. The common direct referencing method is chosen as the control strategy. The continuous current mode buck converter is selected for the PVE and controlled using the common PI controller. The PVE is simulated using the MATLAB/Simulink simulation platform. The next section discusses the control strategy used in the PVE. Then, the design of the MPPT converter is shown in the following section. The results and discussion are covered in the next section. The paper ends with a conclusion.

\section{PROPOSED PHOTOVOLTAIC EMULATOR}

The PVM used for the PVE is a simplified version of the PVM adder method. Instead of using multiple standard PVM, the irradiance $(G)$, module temperature $(T)$, and PV voltage $\left(V_{p v}\right)$ are adjusted so that only one standard PVM able to be represented as multiple standard PVM for the partial shading. The adjustment algorithm is called the partial shading adjuster, as shown in Figure 1. During the partial shading, there are multiple $G$ and $T$ inputs for the PVM $\left(G_{v e c}\right.$ and $\left.T_{v e c}\right)$. The $V_{p v}$ input for the PVM is higher than the open-circuit voltage, $V_{o c}$, of a single PV module since it is $V_{p v}$ in series $\left(V_{p v_{-} s r}\right)$. The function of the partial shading adjuster is to select a suitable $G$ and $T\left(G_{i}\right.$ and $\left.T_{i}\right)$ for the one standard PVM. Then, the $V_{p v}$ is reduced to for the use of the one PVM ( $V_{p v}$ needs to be equal to or lower than $V_{o c}$ for a valid PVM). The new $V_{p v}$ is called adjusted $V_{p v}, V_{p v \_a d j}$. The final output for the PVM is the series PV current, $I_{p v_{-} s r}$.

The $I_{p v_{\_} s} r$ becomes the reference current, $I_{r e f}$, for the PI controller. The $I_{r e f}$ is compared with the output current, $I_{o}$, from the buck converter to obtain the error for the PI controller. The PI controller uses the error to produce the corresponding duty cycle, $d$. The pulse width modulation, PWM, use the $d$ and produce the switching pulse, $s p$, for the buck converter. The buck converter produces the $I_{o}$ according to the $I_{r e f}$. The corresponding output voltage, $V_{o}$, from the buck converter is sent to the partial shading adjuster to become $V_{p v_{-} s} r$.

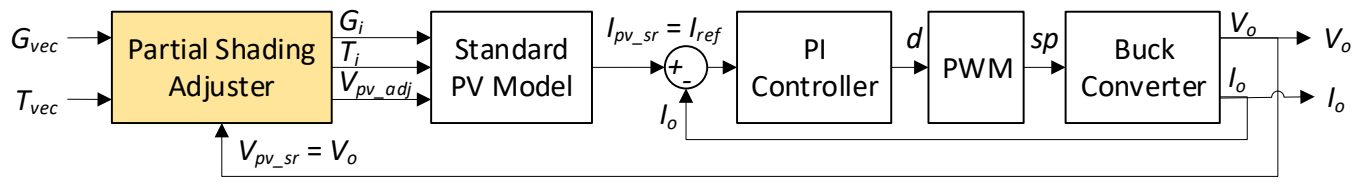

Figure 1. The block diagram of the proposed PVE with partial shading capability by adding the partial shading adjuster 


\subsection{Photovoltaic model}

The PVM consists of two components, which are the standard PVM and the partial shading adjuster. The purpose of the standard PVM is to compute a standard I-V characteristic curve without partial shading. While the function of the partial shading adjuster is to receive multiple irradiance and temperature input, select one irradiance and one temperature, and sent it to a single standard PVM. The selection allows the production of the partial shading characteristic.

\subsubsection{Standard photovoltaic model}

The mathematical characteristic equation for the standard PVM is presented using (1), which calculate the photovoltaic current, $I_{p v}$ [11], [12]. It is based on the single diode model with a series resistor, which is widely used in the PVE application due to the low computation burden [13]-[15]. Commonly, the parallel resistor, $R_{p}$, is considered in the single diode PVM. Nonetheless, it is not applicable for the partial shading adjuster [10]. The Amerisco 80J-B PV module is chosen for the simulation, in which the number of PV cells in a module, $n_{s}$, is 72 [16]. The $K_{t v}$ and temperature coefficient short circuit current, $K_{t i}$, are $-0.16 \mathrm{~V} /{ }^{\circ} \mathrm{C}$ and $0.002 \mathrm{~A} /{ }^{\circ} \mathrm{C}$, respectively. The $\mathrm{PV}$ module has the maximum power point voltage and current at the STC $\left(V_{m p \_s t c}\right.$ and $\left.I_{m p_{-} s t c}\right)$ at $35.8 \mathrm{~V}$ and $2.23 \mathrm{~A}$, respectively. The open-circuit voltage and short circuit current at the STC ( $V_{\text {oc_stc }}$ and $\left.I_{s c_{-} s t c}\right)$ are $44.4 \mathrm{~V}$ and $2.32 \mathrm{~V}$, respectively.

$$
I_{p v}=I_{p h}-I_{s}\left[\exp \left(\frac{V_{p v}+I_{p v} R_{s}}{A V_{t}}\right)-1\right]
$$

Where $I_{p h}$ is the photo-generation current, $V_{p v}$ is the PV voltage, $I_{s}$ is the saturated current, $V_{t}$ is the thermal voltage, and $A$ is the ideality factor.

\subsubsection{Partial shading adjuster}

The partial shading adjuster is an essential part of the PVE to produce partial shading. The algorithm starts by loading the parameters of the PV module and constants, as presented in Figure 2 . The $I_{p h}$ for the first $G$ and $T\left(G_{l}\right.$ and $\left.T_{l}\right)$ is calculated. Then, the $V_{t}$ and $I_{s}$ are evaluated, respectively. Then, the $I_{p h}$ for the following $G$ and $T$ are calculated until the $n_{s}$ is achieved. At the same time, the critical PV voltage, $V_{p v_{-} c r i}$, is determined using (2) and (3). Then, the sum of PV voltage, $V_{p v_{-} s u m}$, is calculated using (4). The $V_{p v_{-} c r i}$ is compared with the $V_{p v_{-} s r}$. If the $V_{p v_{-} s r}$ is smaller than $V_{p v_{-} s u m}$, the $V_{p v_{-} s u m}$ is updated by subtracted with $V_{p v_{-} c r i}$ and the $V_{p v_{-} a d j}$ is calculated using (5). This condition occurs when the operating point of the PVE is located on the I-V characteristic curve for the highest $G$.

$$
\begin{aligned}
& V_{p v_{-} \text {cri }}(i)=A B V_{t}(T(i))-I_{p h}(G(i), T(i)) R_{s} \\
& B=I n\left[\frac{I_{p h}(G(i), T(i))-I_{p h}(G(i+1), T(i+1))}{I_{s}(T(i))}+1\right] \\
& V_{p v_{-} s u m}=\sum_{i=1}^{i}\left[V_{p v_{-} c r i}(i)\right]+(i-1)^{i_{a d j}} V_{p v_{-} c r i \_a d j} \\
& V_{p v_{-} a d j}=V_{p v_{-} s r}-V_{p v_{-} s u m}
\end{aligned}
$$
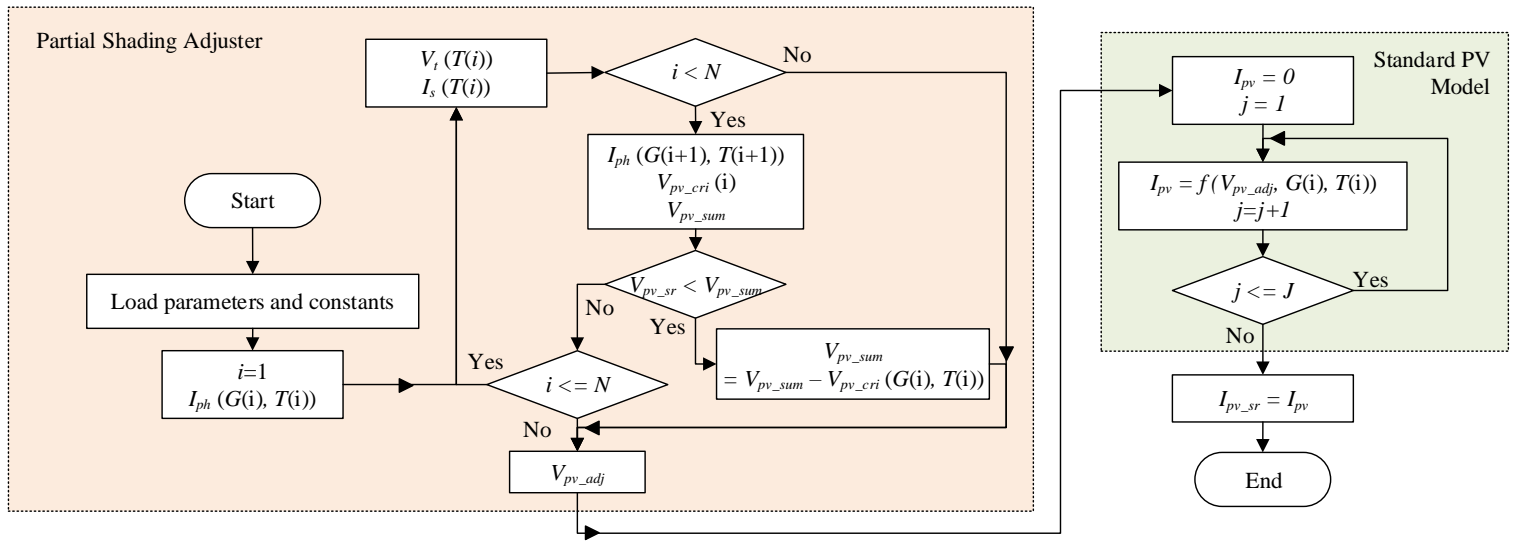

Figure 2. The flowchart of the PVM with the partial shading capability based on the partial shading adjuster method 
If the $V_{p v_{-} s r}$ is equal to or larger than $V_{p v_{-} c r i}$, the operating point of the PVE is located on the I-V characteristic curve for the second-highest and lower $G$. In this condition, the algorithm checks whether the current partial shading adjusted, $i$, is equal to or lower than the $N$. If the condition is not true, this means that the computation is already at the lowest $G$ and the $V_{p v_{-} a d j}$ is calculated using (5). If the condition is true, this means that the computation is between the highest $G$ and the lowest $G$. For this condition, the computation is repeated until the $V_{p v_{-} s r}$ is smaller than $V_{p v_{-} c r i}$.

After the computation of the partial shading adjuster is completed, the $V_{p v_{-} a d j}, G_{i}$, and $T_{i}$ are produced and used by the standard PVM. Since the standard PVM is based on an implicit equation, the iteration method such as the Newton-Raphson method is needed. Using the Newton-Raphson method, (1) is iterated until the number of iterations for the standard PVM, $J$, is achieved. In the end, the $I_{p v}$ becomes the $I_{p v_{-} s r}$.

\subsection{Buck converter}

The PVE requires a power converter to work. The power converter used for the PVE is commonly the buck converter due to the low passive components requirement and high-power efficiency [6], [17], [18]. The equivalent circuit of the buck converter provided in Figure 3 contains parasitic resistors for a more realistic simulation. There are two parts in designing the buck converter, which is the design of the passive element and the controller for the buck converter.

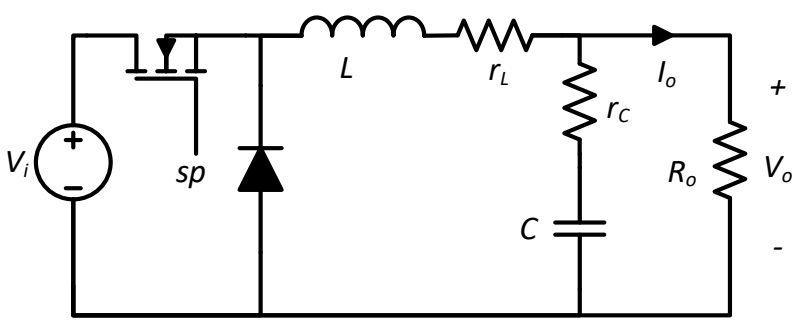

Figure 3. The topology of the buck converter with parasitic resistors

The design of the buck converter for the PVE is based on the conventional buck converter [19], [20]. The first parameter calculated is the input voltage, $V_{i}$ using (6). The $V_{i}$ is affected by the maximum $V_{o c}$, $V_{\text {oc_max }}$, and maximum $d, d_{\max }$. Based on the simulation of the PVM, the $V_{\text {oc_max }}$ is $195.6 \mathrm{~V}$. While the $d_{\max }$ is set to 0.9 . The calculated $V_{i}$ is $217.3 \mathrm{~V}$. Since the calculation does not consider the nonideality factor, a higher voltage needs to be chosen, which is $250 \mathrm{~V}$.

$$
V_{\mathrm{i}}=\frac{V_{o c} \max }{d_{\max }}
$$

The inductance, $L$, design is important to maintain continuous current operation. This is essential especially for the PI controller design since a different controller is needed if the buck converter operates in the discontinuous current mode. The $V_{o_{-} \max }$ and the maximum output resistance, $R_{o_{-} \max }$, balance needs to be considered in the design. In the ideal condition, the $R_{o_{-} \max }$ is infinity. Nonetheless, the buck converter cannot be controlled when the $R_{O_{-} \max }$ is infinity [19]. Therefore, a certain limit is chosen, which is $700 \Omega$. This $R_{O_{-} \max }$ is chosen because it covers the most area in the I-V characteristic curve. Based on the $R_{o_{-} \max }$, the output voltage corresponding to $R_{o_{-} \max }, V_{o_{-} R o_{-} \max }$, is obtained from the PVM. Using (7), the required $L$ is $3 \mathrm{mH}$, which the switching frequency, $f_{s}$, is $20 \mathrm{kHz}$. The corresponding internal resistance of the inductor, $r_{L}$, is $0.9 \Omega$.

$$
L=\frac{\left(1-\frac{V_{O_{-} R o \_ \text {max }}}{V_{i}}\right) R_{O_{-} \max }}{2 f_{S}}
$$

The capacitance, $C$, is designed to operate the buck converter at the desired ripple factor. The chosen output voltage ripple factor, $\gamma_{V o}$, for the PVE is $0.5 \%$ [21]. Based on (8), the $C$ required is $36 \mu \mathrm{F}$, which minimum $D, d_{\min }$, is 0.01 . The corresponding internal resistance of the capacitor, $r_{C}$, is $0.3 \Omega$.

$$
C=\frac{1-d_{\min }}{8 L \gamma_{V_{o}} f_{S}^{2}}
$$


To design the PI controller, the transfer function of the power converter is needed. The transfer function of the buck converter, $G_{b}(s)$, is needed, as provided in (9) [18], [22]. The $G_{b}(s)$ has the $I_{o}$ as of the output since the current-controlled direct referencing method is used for this PVE. For the transfer function of the PI controller, $G_{c}(s)$, it can be presented as (10). Using the automatic tuning function provided by the MATLAB/Simulink, the proportional and integral gains $\left(K_{p}\right.$ and $\left.K_{i}\right)$ are 0.0001 and 39, respectively.

$$
\begin{aligned}
& G_{b}(s)=\frac{\hat{\imath}_{o}(s)}{\hat{d}(s)}=\frac{V_{i}}{R_{o}} \frac{\frac{1}{L C}}{s^{2}+\frac{1}{R_{o} C} s+\frac{1}{L C}} \\
& G_{c}(s)=\frac{\hat{d}(s)}{\hat{e}_{f}(s)}=K_{p}+K_{i} / s
\end{aligned}
$$

\section{RESULTS AND DISCUSSION}

There is five performance analysis conducted for the proposed PVE. This performance analysis is conducted to ensure the direct referencing method control strategy able to cope with the partial shading adjuster modification. The accuracy, load, irradiance, stability, and efficiency tests are conducted using a resistive load. While the compatibility test is conducted using the MPPT converter as the load for the PVE, which the resistive load is removed from the simulation.

\subsection{Accuracy test}

The accuracy is an essential aspect when it comes to PVE. The PVE is considered accurate if the operating points fall on the I-V characteristic curve of the PV. Three types of accuracy tests can be conducted on the PVE. These can be either by comparing the $V_{o}$ and $I_{o}$ of the PVE with the $V_{p v}$ and $I_{p v}$ of the PVM [23], [24], PV module [25], or both PVM and PV module [11]. The comparison with the PV module evaluates the accuracy of the control strategy and PVM used in the PVE. While the comparison with the PVM only evaluates the accuracy of the control strategy used in the PVE. Since the paper focused on the accuracy of the control strategy and not the accuracy of the PVM, the $V_{o}$ and $I_{o}$ of the PVE are compared with the $V_{p v}$ and $I_{p v}$ of the PVM.

The comparison of the I-V characteristic curves produced by the PVE and PVM are shown in Figure 4. The result shows that the $V_{o}$ and $I_{o}$ produced by the PVE is on the I-V characteristic curve of PV. This show that the proposed PVE has high accuracy. The I-V characteristic of the PVE is in the discrete form because the accuracy of the PVE becomes lower if the variable load is sweep from zero to infinity. This is due to the slow transient response of the PVE. The PVE requires a certain time to achieve a steady-state. Therefore, the $V_{o}$ and $I_{o}$ of the PVE are recorded after the steady-state is achieved with multiple fixed loads. There is also no short-circuit ( $R_{o}$ is zero) and open-circuit ( $R_{o}$ is infinity) tests conducted on the PVE. This is because the buck converter cannot work properly during this condition. When the $R_{o}$ is equal to zero, the $V_{o}$ needs to be zero, which then produce zero $I_{o}$ if a buck converter is used. However, the $I_{p v}$ from the PVM is not zero when $V_{p v}$ equals to zero, which means that the PVE fails to emulate the short-circuit test. If the $R_{o}$ is infinity, the $V_{o}$ cannot be regulated and operates near to $V_{i}$. A different type of converter is needed in order to operate at these points.

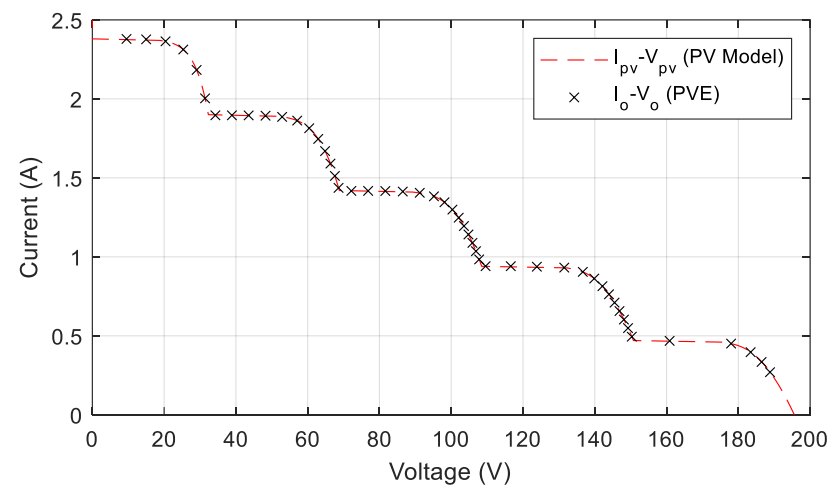

Figure 4. The comparison of the I-V characteristic curve of the PVM and PVE 


\subsection{Load test}

The load test is conducted on the PVE to analyse the transience performance and stability during load changes. A good PVE can change to a new operating point without any oscillation at a fast rate. By referring to Figure 5 (a), the load starts at $30 \Omega$. At $0.2 \mathrm{~s}$, the load is stepped up to $160 \Omega$ for $0.2 \mathrm{~s}$. Then the load is stepped down back to $30 \Omega$. The waveforms of the Vo and Io of the PVE are recorded in Figure 5 (a) and Figure 5 (b), respectively. The percentage overshoot, \%OS, of the is observed and it is calculated using (11) [26]. A PVE needs to have zero or low \%OS to avoid damaging the load or the components in the PVE. Another factor that needs to be considered is the settling time, ts, which is used to analyse the transient performance of the PVE, which is defined as the time taken for the Io to be within $2 \%$ of its steady-state value.

$$
\% \mathrm{OS}=\frac{I_{o(\max )}-I_{o(s s)}}{I_{o(s s)}} \times 100 \%
$$

Where $I_{o(\max )}$ is the maximum output current overshoot and $I_{o(s)}$ is the steady-state output current.

Based on Figure 5 (b), when the load is stepped down from $160 \Omega$ to $30 \Omega$, there is a large $I_{o}$ overshoot occur. Using (11), the \%OS is $147.7 \%$. The large $I_{o}$ overshoot is caused by the $C$ that try to maintain $V_{o}$ after the load is stepped down. This overshoot cannot be avoided when the buck converter is used for the PVE. Nonetheless, the $C$ is only $36 \mu \mathrm{F}$ and the $I_{o}$ should be reduced quickly. However, the $I_{o}$ waveform shows that it takes $43.4 \mathrm{~ms}$ to achieve a steady-state. The slow response is due to the constraint of the PI controller. To reduce the duration of the overshoot, a faster and more robust controller like fuzzy logic or shift controllers [20]. The result shows the $t_{s}$ during the beginning of the operation is $44.1 \mathrm{~ms}$. When the load is stepped up and down, the $t_{s}$ is $80.5 \mathrm{~ms}$ and $43.4 \mathrm{~ms}$, respectively. The results show that the $t_{s}$ is faster when the load is stepped down compared to when the load is stepped up. The slow response during a high load condition is due to the limitation of the PI controller. The PI controller is designed at the lowest load to avoid unstable output. If the PI controller is designed at the higher load condition, the output becomes unstable when the load is low. Nonetheless, the PI controller alone does not affect the $t_{s}$ for the PVE [20]. If the effect of PI controller alone is accounted, the $t_{s}$ increases as the $V_{o}$ increases. By referring to Figure 6 , this relationship does not apply. This is because the control strategy used in the PVE affects the $t_{s}$ for the PVE. Since the direct referencing control strategy is used for the PVE, the $t_{s}$ becomes higher at the local and global MPP. The $t_{s}$ becomes lower when the operation leaves the MPP and move to the constant voltage region. A robust PVE should maintain a constant $t_{s}$ at the various operating point.

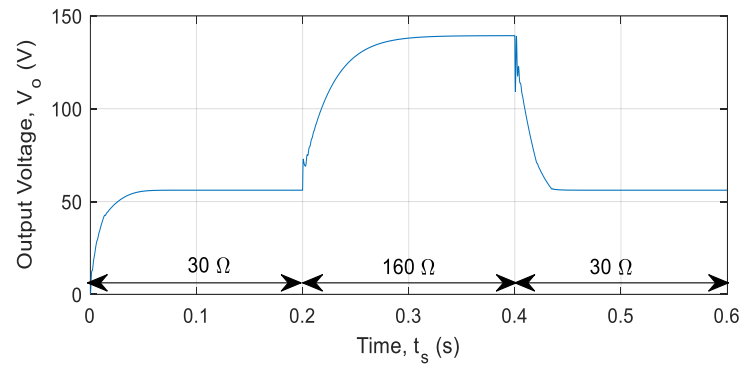

(a)

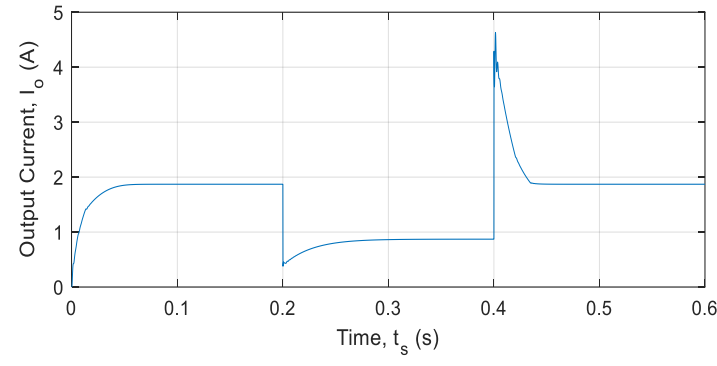

(b)

Figure 5. The time-domain response of the PVE when the load is stepped up from $30 \Omega$ to $160 \Omega$ at $0.2 \mathrm{~s}$ and stepped down from $160 \Omega$ to $30 \Omega$ at $0.4 \mathrm{~s}$ (a) output voltage waveform (b) output current waveform

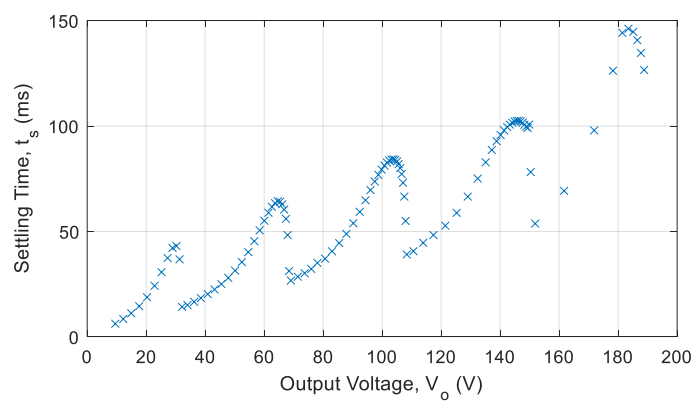

Figure 6. The settling time of the output voltage of the PVE at various load condition 


\section{CONCLUSION}

The PVM requires a high computation since it is based on an implicit equation that requires multiple iterations. To produce partial shading, several PVMs need to be used, which further increases the computation burden. Nonetheless, the partial shading adjuster allows partial shading capability with only a single PVM. This gives an advantage for the PVE because the PVE able to operate in real time and requires a low computation to work properly. The partial shading adjuster is a new concept and is not being tested in the PVE. Based on the simulation results, this adjuster is suitable for the PVE. The accuracy test shows the PVE can imitate the I-V characteristic curve produced by the PVM. This result not only shows combining the partial shading adjuster with the PVE has produced high accuracy results but also shows it is stable during the steady state operation. The result shows that the transient response becomes slower as the load increases. There is also a current spike that occurs during the load stepped down. A different power converter, closedloop controller, and control strategy are needed to improve the PVE. In conclusion, the partial shading adjuster can work with the PVE since it is accurate. The transient response of the PVE requires improvement due to the slow response at a high load and a high current spike when the load decreases.

\section{ACKNOWLEDGEMENTS}

The gratitude to Universiti Teknologi Malaysia (UTM) for providing funding, UTM Encouragement Research (UTMER) Grant under vote Q.J130000.2651.18J39. Lastly, appreciation to colleagues that contributed to the completion of the research.

\section{REFERENCES}

[1] O. Midtgard, "A simple photovoltaic simulator for testing of power electronics," 2007 European Conference on Power Electronics and Applications, 2007, pp. 1-10, doi: 10.1109/EPE.2007.4417450.

[2] A. Zegaoui, M. Aillerie, P. Petit, and J.-P. Charles, "Universal Transistor-based hardware SIMulator for real time simulation of photovoltaic generators," Solar Energy, vol. 134, pp. 193-201, 2016, doi: 10.1016/j.solener.2016.05.005.

[3] S. Mishra, S. Raju, A. Kshirsagar and N. Mohan, "An Extremely Low-Cost Multi-Panel PV Emulator for Research and Education," 2018 IEEE Energy Conversion Congress and Exposition (ECCE), 2018, pp. 4760-4765, doi: 10.1109/ECCE.2018.8557361

[4] T. D. Mai, S. De Breucker, K. Baert, and J. Driesen, "Reconfigurable emulator for photovoltaic modules under static partial shading conditions," Solar Energy, vol. 141, pp. 256-265, January 2017, doi: 10.1016/j.solener.2016.11.050.

[5] R. Kadri, H. Andrei, J.-P. Gaubert, T. Ivanovici, G. Champenois, and P. Andrei, "Modeling of the photovoltaic cell circuit parameters for optimum connection model and real-time emulator with partial shadow conditions," Energy, vol. 42, no. 1, pp. 5767, 2012, doi: 10.1016/j.energy.2011.10.018

[6] M. Alaoui, H. Maker, A. Mouhsen, and H. Hihi, "Photovoltaic emulator of different solar array configurations under partial shading conditions using damping injection controller," International Journal of Power Electronics and Drive System, vol. 11, no. 2, pp. 1019-1030, June 2020, doi: 10.11591/ijpeds.v11.i2.pp1019-1030.

[7] A. Xenophontos, J. Rarey, A. Trombetta and A. M. Bazzi, "A flexible low-cost photovoltaic solar panel emulation platform," 2014 Power and Energy Conference at Illinois (PECI), 2014, pp. 1-6, doi: 10.1109/PECI.2014.6804542.

[8] C.-C. Chen, H.-C. Chang, C.-C. Kuo, and C.-C. Lin, "Programmable energy source emulator for photovoltaic panels considering partial shadow effect," Energy, vol. 54, pp. 174-183, 2013, doi: 10.1016/j.energy.2013.01.060.

[9] M. C. Di Piazza and G. Vitale, "Photovoltaic field emulation including dynamic and partial shadow conditions," Applied Energy, vol. 87, no. 3, pp. 814-823, 2010, doi: 10.1016/j.apenergy.2009.09.036.

[10] R. Ayop, C. W. Tan, M. S. A. Mahmud, S. N. Syed Nasir, T. Al-Hadhrami, and A. L. Bukar, "A simplified and fast computing photovoltaic model for string simulation under partial shading condition," Sustainable Energy Technologies and Assessments, vol. 42, p. 100812, 2020, doi: 10.1016/j.seta.2020.100812.

[11] R. Ayop and C. W. Tan, "An Adaptive Controller for Photovoltaic Emulator using Artificial Neural Network," Indonesian Journal of Electrical Engineering and Computer Science, vol. 5, no. 3, pp. 556-563, 2017, doi: 10.11591/ijeecs.v5.i3.pp556-563.

[12] I. Moussa, A. Bouallegue and A. Khedher, "Development of a low cost PV simulator based on FPGA technology," 2017 International Conference on Green Energy Conversion Systems (GECS), 2017, pp. 1-6, doi: 10.1109/GECS.2017.8066243.

[13] U. K. Shinde, S. G. Kadwane, R. K. Keshri and S. P. Gawande, "Dual Mode Controller-Based Solar Photovoltaic Simulator for True PV Characteristics," in Canadian Journal of Electrical and Computer Engineering, vol. 40, no. 3, pp. 237-245, Summer 2017, doi: 10.1109/CJECE.2017.2708721.

[14] Y. -T. Seo, J. -Y. Park and S. -J. Choi, "A rapid I-V curve generation for PV model-based solar array simulators," 2016 IEEE Energy Conversion Congress and Exposition (ECCE), 2016, pp. 1-5, doi: 10.1109/ECCE.2016.7854764.

[15] B. D. Patel and A. Rana, "A pole-placement approach for buck converter based PV array Emulator," 2016 IEEE 1st International Conference on Power Electronics, Intelligent Control and Energy Systems (ICPEICES), 2016, pp. 1-5, doi: 10.1109/ICPEICES.2016.7853397.

[16] Ameresco Solar, "Ameresco Solar 80W (24V) Photovoltaic Modules - 80J-B (24V)," ed: Ameresco Inc., 2014

[17] D. Subhi and R. Thabit, "A New Low Cost Solar Array Emulator Based on Fuzzy and 32-Bit Microcontroller," International Journal of Science and Engineering Investigations, vol. 9, no. 101, 2020.

[18] M. Alaoui, H. Maker, A. Mouhsen, and H. Hihi, "Real-time emulation of photovoltaic energy using adaptive state feedback control," SN Applied Sciences, vol. 2, p. 492, 2020, doi: 10.1007/s42452-020-2294-2.

[19] D. W. Hart, Power Electronics, New Delhi : Tata McGraw-Hill, 2011.

[20] R. Ayop, C. W. Tan, and A. L. Bukar, "Simple and fast computation photovoltaic emulator using shift controller," IET Renewable Power Generation, vol. 14, no. 11, pp. 2017-2026, 2020, doi: 10.1049/iet-rpg.2019.1504. 
[21] S. M. Azharuddin et al., "A Near Accurate Solar PV Emulator Using dSPACE Controller for Real-time Control," in Energy Procedia, vol. 61, pp. 2640-2648, 2014, doi: 10.1016/j.egypro.2014.12.266.

[22] S. E. I. Remache, A. Y. Cherif, and K. Barra, "Optimal cascaded predictive control for photovoltaic systems: application based on predictive emulator," IET Renewable Power Generation, vol. 13, no. 15, pp. 2740-2751, 2019, doi: 10.1049/iet-rpg.2019.0068.

[23] R. Ayop, C. W. Tan, and C. S. Lim, "The Resistance Comparison Method using Integral Controller for Photovoltaic Emulator," International Journal of Power Electronics and Drive Systems, vol. 9, no. 2, 2018, doi: 10.11591/ijpeds.v9.i2.pp820-828.

[24] I. Moussa, A. Khedher, and A. Bouallegue, "Design of a Low-Cost PV Emulator Applied for PVECS," Electronics, vol. 8, no. 2, p. 232, 2019, doi: 10.3390/electronics8020232.

[25] Y. Mallal, L. El Bahir, and T. Hassboun, "High-Performance Emulator for Fixed Photovoltaic Panels," International Journal of Photoenergy, vol. 2019, p. 3951841, 2019, doi: 10.1155/2019/3951841.

[26] N. S. Nise, Control Systems Engineering vol. 7th Edition, New Jersey, United States: John Wiley \& Sons, Inc., 2015.

\section{BIOGRAPHIES OF AUTHORS}
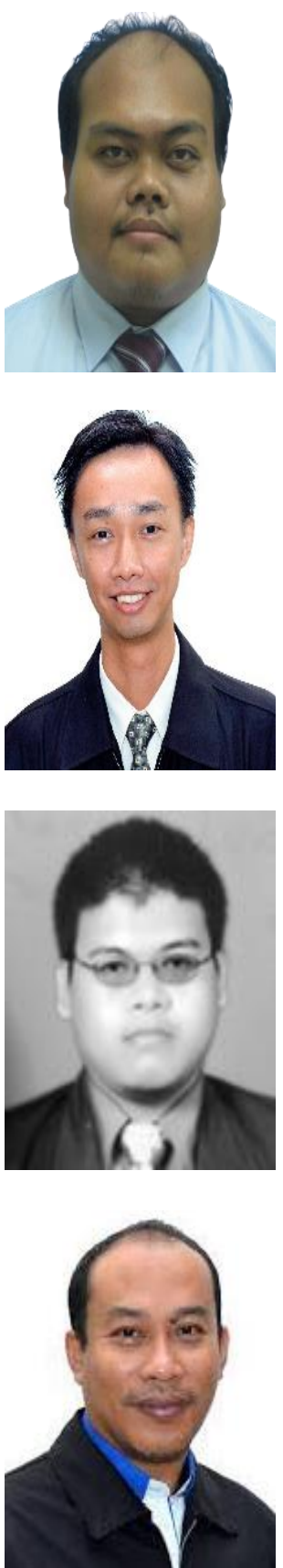

Razman Ayop (iD \& SC P received the bachelor's degree in electrical engineering with firstclass honours, the master's degree in electrical engineering with specialization in power system, and the $\mathrm{PhD}$ degree in electrical engineering from Universiti Teknologi Malaysia (UTM), Johor, Malaysia, in 2013, 2015, and 2018, respectively. He is a Senior Lecturer with UTM and a member of Power Electronics and Drives Research Group, School of Electrical Engineering, Faculty of Engineering, UTM. His research interests include renewable energy and power electronics. He can be contacted at email: razman.ayop@utm.my.

Chee Wei Tan (D) 8 SC $P$ received his B.Eng. degree in electrical engineering (first class honors) from Universiti Teknologi Malaysia (UTM), in 2003 and a Ph.D. degree in electrical engineering from Imperial College London, London, U.K., in 2008. He is currently an associate professor at Universiti Teknologi Malaysia and a member of the Power Electronics and Drives Research Group, School of Electrical Engineering, Faculty of Engineering. His research interests include the application of power electronics in renewable/alternative energy systems, control of power electronics and energy management system in microgrids. He can be contacted at email: cheewei@utm.my.

Syed Norazizul Syed Nasir (D) 8 sc $\mathrm{P}$ received the B.Eng. (Hons) degree in electrical engineering in 2008, M.Eng. degree in electrical (power) engineering in 2014 and $\mathrm{PhD}$ degree in electrical (power) engineering in 2019 from Universiti Teknologi Malaysia (UTM), Johor Bahru, Malaysia. He works as electrical engineer in high voltage protection since 2008 until 2019 at Tenaga Nasional Berhad. He is currently senior lecturer in School of Electrical Engineering at Universiti Teknologi Malaysia (UTM). His current research interests include power system optimization, power system stability, power system protection and harmonic mitigation and their control methods. He can be contacted at email: syednorazizul@utm.my.

Mohd Zaki Daud (iD IS SC P is a Lecturer at School of Electrical Engineering, Faculty of Engineering, Universiti Teknologi Malaysia since 1997. He received his BEng in Electrical Engineering from University of Southampton, UK in 1995 and MSc in Electric Power from University of Newcastle upon Tyne in 1997. Currently he is embarking a PhD in Electrical Engineering. His current research interest includes harmonics in power electronics-based power sytem, estimation techniques in electric drives, modelling of electromagnetic processes using soft computing techniques, renewable energy and engineering education. He can be contacted at email: mdzaki@utm.my. 


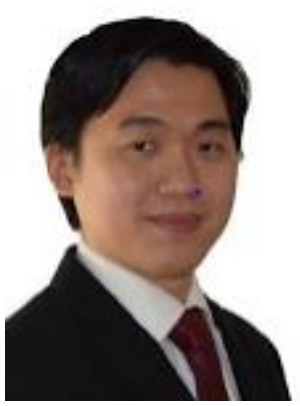

Lau Kwan Yiew (iD) 8 SC $\mathrm{P}$ received his B.Eng. degree in electrical engineering (first class honors) and M.Eng. degree in electrical power engineering from Universiti Teknologi Malaysia in 2007 and 2010, respectively. In 2013, he received his Ph.D. degree in electronics and electrical engineering from the University of Southampton, UK. He is currently an associate professor at the Institute of High Voltage and High Current, Universiti Teknologi Malaysia. His research interests include high voltage engineering, dielectric materials, and renewable energy systems. He can be contacted at email: kwanyiew@utm.my.

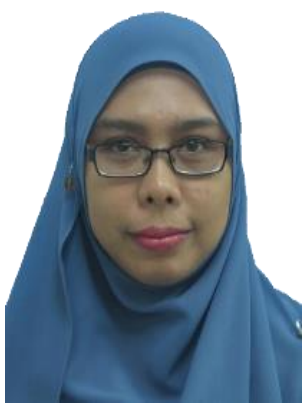

Norjulia Mohamad Nordin (D) SC S S received her degree in bachelor of electrical engineering from the Universiti Teknologi Malaysia (UTM) in 2006 and the Master in Engineering Science from the University of New South Wales in 2008. She then received her Ph.D in electrical engineering from UTM in 2016. Currently, she is a Senior Lecturer at the Faculty of Engineering, Universiti Teknologi Malaysia (UTM). Her current research interests are in AC motor drives/electrical drives, power electronics applications, electrical machines and renewable energy conversion. She can be contacted at email: norjulia@utm.my.

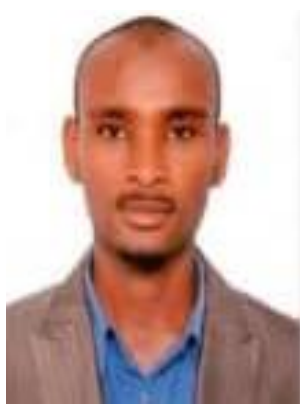

Abba Lawan Bukar (DD SC SC is a lecturer at the Department of Electrical and Electronic Engineering, University of Maiduguri. His research interest includes renewable energy technologies, energy management optimization. He can be contacted at email: abbalawan9@gmail.com. 